\title{
[Full Paper]
}

\section{Tissue specificity of tropomyosin isoform in the mussel, Mytilus galloprovincialis}

\author{
Atsuko Itoh ${ }^{1}$ and Masakatsu Fujinoki ${ }^{2}$
}

\begin{abstract}
SUMMARY
In the mussel, Mytilus galloprovincialis, there were three kinds of tropomyosin isoforms, which were designated as TM1, TM2 and TM3, respectively. It had been reported that TM1 was contained as only tropomyosin isoform and major component in the muscle tissues such as adductor and cardiac muscles, it was confirmed as the major isoform in adductor, cardiac and anterior pedal retractor muscles, and in the mantle and gills. In this present study, meanwhile, TM2 and TM3 were detected as two new isoforms in the mantle and gills. TM2 and TM3 existed only in the mantle and in both the mantle and gills, respectively. Both TM2 and TM3 were minor isoforms compared to TM1. TM2 had almost the same molecular weight as TM1 whereas TM3 had lower molecular weight than TM1. Moreover, TM3 had more basic isoelectric point than TM1 and TM2.
\end{abstract}

Key words: mussel, tissue specificity, tropomyosin, isoform.

\section{INTRODUCTION}

Tropomyosin is an actin-binding protein that exists in muscle and non-muscle cells. The physiological function of tropomyosin is known in skeletal muscle of vertebrate, where tropomyosin in association with troponin complex (i.e.troponin I, T, and C) functions as a co-regulator of muscle contraction ${ }^{1-4)}$. Generally, there are multiple tropomyosin isoforms that expressed by multiple genes and by alternative splicing of transcripts of those genes in many animals $^{2-9}$. Moreover, the isoforms show a tissue-specific distribution in many animals; for example, human ${ }^{10)}$, chicken $^{11)}$, salmonid fish ${ }^{12)}$, lobster ${ }^{13)}$, bivalve ${ }^{14-16)}$, sea urchin $^{17)}$, and sea anemone ${ }^{18}$. Although it is likely that tissue-specific distribution is associated with the roles of the isoforms in the tissues, the functions of tropomyosin itself in the absence of troponin are not well known.

The heterogeneity and tissue specificity of tropomyosin isoforms has been examined in several species of bivalves $^{14-16)}$. In Patinopecten yessoensis (scallop) and Mimachlamys nobilis (senatorial scallop), three tropomyo- sins have been isolated from adductor muscle and cardiac muscle ${ }^{15,16)}$. One isoform was striated-muscle-specific and the other two existed in adductor smooth muscle and cardiac muscle. In six other species [Scapharca broughtonii (ark shell), Atrina pectinata (surf clam), Crassostrea gigas (Pacific oyster), Mactra chinensis (Chinese mactra), Tresus keenae (Trough shell) and Meretrix lammarckii (orient (clam) ${ }^{14,16)}$ ], only two tropomyosin isoforms have been found in muscle tissues. In A. pectinata, M. chinensis, $T$. keenae and M. lammarckii, one of the two isoforms was adductor-muscle-specific and the other existed in both adductor and cardiac muscles ${ }^{14,16)}$. In S. broughtonii and $C$. gigas, however, both isoforms existed in adductor and cardiac muscles, although the localization in adductor muscle differed between the two species ${ }^{14)}$. In M. galloprovincialis (mussel), interestingly, only one tropomyosin had been found in both adductor muscle and cardiac muscle ${ }^{14}$.

Although tropomyosin found from many bivalves showed tissue specific distributions ${ }^{14-16)}$, only mussel tropomyosin did not show $\mathrm{it}^{14)}$. In order to examine whether mussel tropomyosin does not show tissue specific distribution, in the

\footnotetext{
${ }^{1}$ Department of Biology, Keio University.

${ }^{2}$ Department of Physiology, School of Medicine, Dokkyo Medical University.

Correspondence address: Atsuko Itoh; Department of Biology, Keio University, 4-1-1 Hiyoshi, Kouhoku-Ku, Yokohama, Kanagawa 223-8521, Japan.

E-mail: itoh@hc.cc.keio.ac.jp

Abbreviations: TCA, trichloroacetic acid; Tris, Tris (hydroxymethyl) aminomethane; SDS, sodium dodecyl sulfate; SDS-PAGE, sodium dodecyl sulfate polyacrylamide gel electrophoresis; PVDF, poly (vinylidene difluoride); PBS, phosphate-buffered saline; IgG, immunoglobulin G; CBB, Coomassie brilliant blue.

(Received March 3, 2008, Accepted May 13, 2008, Published September 15, 2008)
} 
present study, we tried to find tropomyosin from other muscle and non-muscle tissue.

\section{MATERIALS AND METHODS}

\section{Preparation of tropomyosin extracts}

The mussel, M. galloprovincialis was purchased from a fish market and tropomyosin extracts were prepared as described previously ${ }^{14,18)}$. Samples of the anterior pedal retractor muscle, translucent and opaque portions of adductor muscle, cardiac muscle, gills and mantle were suspended in 50 volumes of acetone, minced with scissors, washed seven times with acetone, air dried, and used as acetone powder, which was treated with 100 volumes of $5 \%$ (w/v) trichloroacetic acid (TCA) for 1 hour at room temperature to prevent endogenous proteolysis ${ }^{19)}$. The TCAtreated acetone powder was washed three times with a barbital buffer containing $0.1 \mathrm{M} \mathrm{NaCl}$ and $0.035 \mathrm{M}$ sodium barbital-HCl ( $\mathrm{pH} 8.0$ ), washed six times with acetone, and air dried. Tropomyosin was extracted from the TCA-treated acetone powder using 20 volumes of a $\mathrm{KCl}$ buffer containing $1 \mathrm{M} \mathrm{KCl}, 0.1 \mathrm{M} \mathrm{KH}_{2} \mathrm{PO}_{4}-\mathrm{KOH}(\mathrm{pH} 7.0$ ) and $1 \%$ (v/v) 2mercaptoethanol. After incubation for 14 hours at $4^{\circ} \mathrm{C}$, the $\mathrm{KCl}$ extraction product was centrifuged at $20,000 \times g$ for 1 hour at $4^{\circ} \mathrm{C}$. The supernatant was dialyzed against the barbital buffer, and then re-dialyzed against a solution containing $62.5 \mathrm{mM}$ Tris- $\mathrm{HCl}(\mathrm{pH} 6.8), 2 \%$ (w/v) SDS and 5\% (v/v) 2-mercaptoethanol. After the supernatant was centrifuged at $20,000 \times g$ for 1 hour at $4^{\circ} \mathrm{C}$, it was used as the tropomyosin extract.

\section{Sodium dodecyl sulfate gel electrophoresis (SDS- PAGE)}

SDS-PAGE was carried out according to the method of Laemmli $^{20)}$ using a separating gel of $10 \%$ or $15 \%(\mathrm{w} / \mathrm{v})$ polyacrylamide containing $0.1 \%(\mathrm{w} / \mathrm{v})$ SDS or $0.1 \%(\mathrm{w} / \mathrm{v})$ SDS and $5 \mathrm{M}$ urea.

\section{Two-dimensional urea-shift gel electrophoresis}

Two-dimensional urea-shift gel electrophoresis was carried out according to the method of Carmon et al. ${ }^{21)}$ with some modification. Electrophoresis was performed on $10 \%(\mathrm{w} / \mathrm{v})$ polyacrylamide separating gel containing $0.1 \%(\mathrm{w} / \mathrm{v})$ SDS and $5 \mathrm{M}$ urea in the first dimension and $0.1 \%(\mathrm{w} / \mathrm{v})$ SDS in the second dimension with the Tris-buffer system ${ }^{20}$.

\section{Two-dimensional gel electrophoresis}

Two-dimensional gel electrophoreses with isoelectric focusing (IEF) and SDS gels, and with IEF and SDS/Urea gels were carried out according to the method of Hirabayashi $^{22)}$ with some modifications ${ }^{14)}$. First dimension IEF was performed on cylindrical agarose gel at $4^{\circ} \mathrm{C}$ with a 1:2 mixture of two types of Ampholines ( $\mathrm{pH} \mathrm{4-6}$ and pH 3.5-10, GE Healthcare UK Ltd., Buckingham, UK) as carrier ampholyte. Second dimension SDS and SDS/Urea gel electrophoresis was done with $10 \%$ polyacrylamide gels containing $0.1 \%$ (w/v) SDS with the Tris-buffer system ${ }^{20}$, and $0.1 \%(\mathrm{w} / \mathrm{v})$ SDS and $5 \mathrm{M}$ urea ${ }^{21)}$, respectively.

\section{Immunoblotting}

Immunoblotting was based on the method of Towbin et $\mathrm{al}^{23)}$. After electrophoresis, proteins were transferred to PVDF sheets (Immobilon-P, Millipore Co., Bedford, MA, USA). The blotted membrane was blocked with $5 \%(\mathrm{w} / \mathrm{v})$ skim milk in Tween-PBS containing $0.2 \mathrm{M} \mathrm{NaCl}, 7.2 \mathrm{mM}$ $\mathrm{Na}_{2} \mathrm{HPO}_{4}, 2.8 \mathrm{mM} \mathrm{NaH}_{2} \mathrm{PO}_{4}$, and $0.1 \%$ (w/v) Tween-20 for 1 hour at room temperature, and incubated with either antichicken tropomyosin antiserum (Sigma-Aldrich Co., St Louis, MO, USA) (1:100 dilution with $5 \%$ (w/v) skim milk in Tween-PBS) or anti-Minachlamys nobilis tropomyosin antiserum $^{15)}$ (1:20,000 dilution with $5 \%(\mathrm{w} / \mathrm{v})$ skim milk in Tween-PBS) for 1 hour at room temperature. A horseradish-peroxidase-conjugated anti-rabbit IgG antibody (Wako, Osaka, Japan) (1:20,000 dilution with $5 \%$ (w/v) skim milk in Tween-PBS) was used as the second antibody. Color reaction was carried out using ECL-Plus Western blotting detection reagents (GE Healthcare UK Ltd, Buckingham, UK).

\section{Limited proteolysis with V8 protease}

Limited proteolysis of tropomyosin was carried out according to the method described by Cleveland et $\mathrm{al}^{24)}$. Each tropomyosin isoform was isolated by excising the protein band from the gels after SDS-PAGE with $5 \mathrm{M}$ urea. The protein band and $40 \mathrm{ng}$ of $\mathrm{V} 8$ protease (Wako) were subjected to electrophoresis, and the proteolysis reaction was performed by stopping the electrophoresis for 1 hour at room temperature.

\section{Amino acid sequencing}

After limited proteolysis of tropomyosin, fragments of tropomyosin were transferred to PVDF sheets (Immobilon$\mathrm{P}^{\mathrm{SQ}}$, Millipore Co.) and after CBB staining, they were subjected to amino acid sequencing (Procise Model 491cLC, Applied Biosystems Inc., Foster City, CA, USA). Amino acid sequences were identified using FASTA (http:// fasta.genome.jp).

\section{RESULTS}

\section{Tissue-specific distribution of tropomyosin}

When tropomyosin is extracted from TCA-treated muscle sources, it is detected as a dominant band ${ }^{19)}$. In our previous study ${ }^{14)}$, we found one tropomyosin in the translucent and opaque portions of adductor muscle and in cardiac muscle. In the present study, one tropomyosin was detected as the dominant band from samples of the same muscle tissues (Fig. 1 lanes b-d), as well as in anterior pedal retractor muscle (Fig. 1 lane a). In the mantle and gills, however, there was the tropomyosin that corresponded to the domi- 


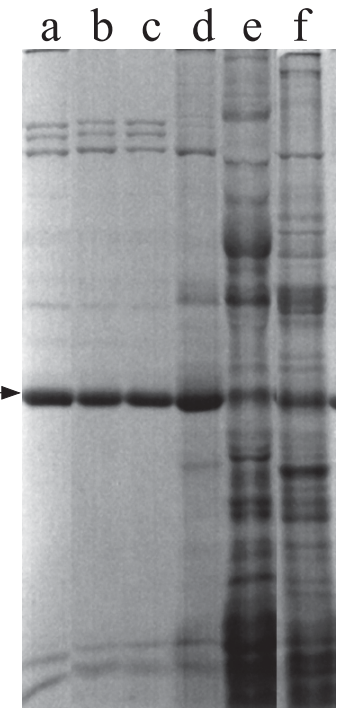

Fig. 1. Tropomyosin obtained from tissues of the mussel, Mytilus galloprovincialis.

Tropomyosin extracts were prepared from TCA-treated acetone powder of (a) anterior pedal retractor muscle, (b) the translucent portion of adductor muscle, (c) the opaque portion of adductor muscle, (d) cardiac muscle, (e) mantle and (f) gills, and subjected to $10 \%$ SDS-PAGE. In (a-c), (d), (e) and (f), $4 \mu \mathrm{L}, 17.5 \mathrm{uL}, 100 \mu \mathrm{L}$ and $70 \mu \mathrm{L}$ of tropomyosin extract were applied, respectively. Arrow indicates tropomyosin.

nant band detected in the other muscle tissues (Fig. 1 lanes a-d) and some new minor bands (Fig. 1 lanes e and f).

In the next step, mussel tropomyosins were subjected to two-dimensional urea-shift gel electrophoresis (Fig. 2). It has been shown that the electrophoretic mobility of tropomyosin on SDS-PAGE is retarded when urea is included in the gel system ${ }^{25}$. Therefore, we can detect tropomyosin as a spot that is separated from the diagonally arranged spots of other proteins on the two-dimensional urea-shift gel electrophoresis. As shown in Fig. 2a-d, only one isoform was detected in anterior pedal retractor muscle, the translucent and opaque portions of adductor muscle and in cardiac muscle, whereas in the mantle and gills (Fig. 2e and f), there was one major spot, which corresponded to the tropomyosin detected in the other muscles, and three or four minor spots.

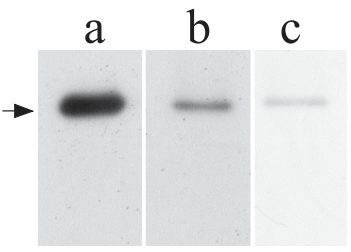

Fig. 3. Immunoblotting of tropomyosin.

Tropomyosin obtained from the translucent portion of adductor muscle was used for immunoblotting with anti-Minachlamys nobilis tropomyosin antiserum (a) and anti-chicken tropomyosin antiserum (b). Lane (c) shows CBB-stained gel. In $(\mathrm{a}-\mathrm{c}), 4 \mu \mathrm{L}$ of 20 -fold dilution of tropomyosin extract were applied. Arrow indicates tropomyosin.

\section{Immunoblotting of tropomyosin}

The band of tropomyosin detected in several muscle tissues (Figs. 1 and 2) reacted strongly to the anti-M. nobilis tropomyosin antiserum (Fig. 3 lane a), but reactivity against the anti-chicken tropomyosin antiserum was very weak (Fig. 3 lane b).

In the samples from the mantle, the major tropomyosin spot and the two minor spots reacted against the anti- $M$. nobilis tropomyosin antiserum (Fig. $4 \mathrm{a}$ and b). The three spots identified as tropomyosin isoforms by immunoblotting were designated TM1, TM2 and TM3. TM1 was the dominant spot and corresponded to the tropomyosin found in retractor muscle, adductor muscle and cardiac muscle. TM2 was the same molecular weight as TM1, and was largely retarded by urea. TM3 had a lower molecular weight than TM1 and TM2. In the samples from the gills, one major spot and one minor spots reacted against the anti-M. nobilis tropomyosin antiserum (Fig. $4 \mathrm{c}$ and d). The major spot corresponded to TM1 and the minor spot with a low molecular weight corresponded to TM3.

\section{Characterization and amino acid sequencing of mussel tropomyosin isoforms}

As shown in Fig. 5a and b, TM1 and TM2 of mussel tropomyosins had the same molecular weight. Their molecular weight was estimated to be approximately 38,000 Da from mobilities of those components on SDS gels with a phos-

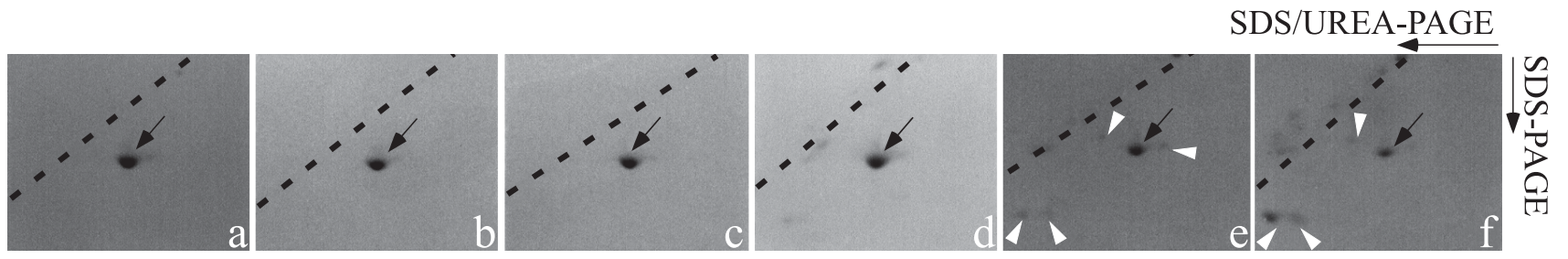

Fig. 2. Two-dimensional urea-shift gel electrophoresis of mussel tropomyosin.

Tropomyosin extracts were prepared from TCA-treated acetone powder of (a) anterior pedal retractor muscle, (b) the translucent portion of adductor muscle, (c) the opaque portion of adductor muscle, (d) cardiac muscle, (e) mantle and (f) gills, and subjected to two-dimensional urea-shift gel electrophoresis. In (a-c), (d), (e) and (f), $5 \mu \mathrm{L}, 20 \mu \mathrm{L}, 50 \mu \mathrm{L}$ and $75 \mu \mathrm{L}$ of tropomyosin extract were applied, respectively. Arrows and white arrowheads show the tropomyosin spot and other spots, respectively, separated from the diagonally arranged spots of proteins. Dotted lines show the diagonal line of the electrophoretogram. 


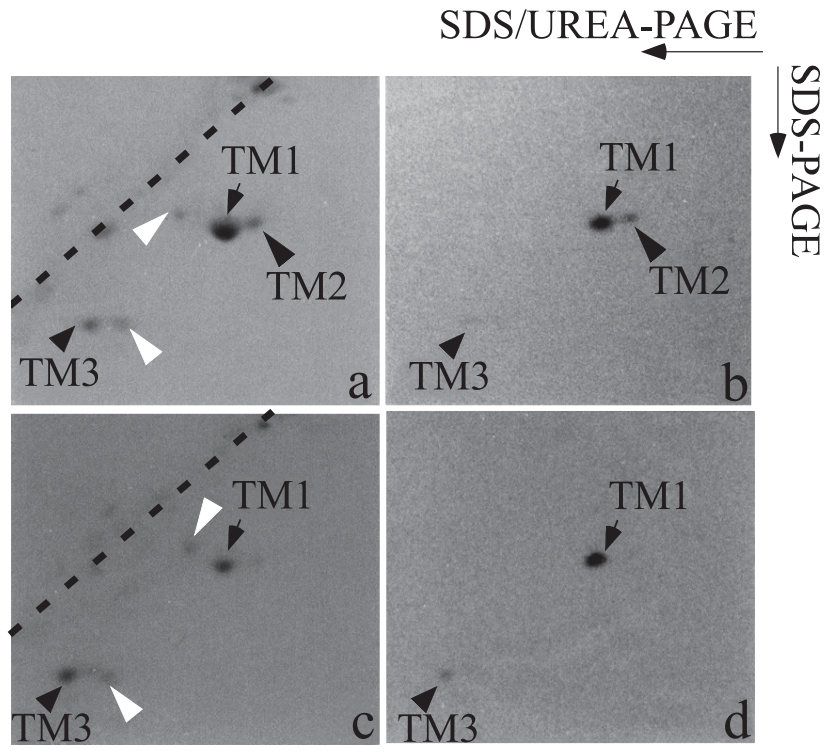

Fig. 4. Immunoblotting of tropomyosin obtained from mantle and gills.

Tropomyosin extracts prepared from the mantle $(\mathrm{a}, \mathrm{b})$ and gills (c, d) were subjected to two-dimensional urea-shift gel electrophoresis, and then immunoblotted using anti-M. nobilis tropomyosin antiserum (b, d). Photographs (a) and (c) show CBB-stained gels. Arrows and arrowheads show the spots separated from the diagonally arranged spots of proteins. Arrows also show one major spot corresponding to the major tropomyosin from muscle tissues. Arrows and arrowheads indicate spots that reacted with anti-M. nobilis tropomyosin antiserum, designated as TM1, TM2 and TM3, respectively. White arrowheads indicate spots that did not react with antiM. nobilis tropomyosin antiserum. Dotted lines show the diagonal line of the electrophoretogram.

phate buffer system ${ }^{26)}$ (data not shown) and with a Tris-HCl buffer system. On the other hand, apparent molecular weight of TM3 was lower than TM1 and TM2 and was estimated to be approximately $31,000 \mathrm{Da}$ from mobilities of those components on SDS gels with a phosphate buffer system $^{26}$ (data not shown) and with a Tris-HCl buffer system. In the next step, mussel tropomyosins were subjected to two-dimensional gel electrophoresis with isoelectric focusing (IEF) and SDS gels, and with IEF and SDS/Urea gels (Fig. 5c, d, e and f). TM1 and TM2 were same pI values, whereas pI value of TM3 was a little basic rather than TM1 and TM2 (Fig. 5d, f). Their pI values were estimated to be approximately 4.5 from mobilities of those components on IEF gels ${ }^{14,22)}$ (data not shown).

Because TM1 had a large volume component, it was purified from adductor muscle using electrophoresis, and digested by limited proteolysis with V8 protease. As shown in Fig. 6A, five fragments were obtained (Fig. 6A) and analyzed for their amino acid sequences (Fig. 6B). EIQSLTDKXSXLEEDXXXSEE and EAQLXAEEAD for fragments 2 and 5 , respectively (Fig. $6 \mathrm{~B}$ ), were the only sequences obtained, and using a database (FASTA) search (Fig. 6C) they were identified as the deduced amino acid sequence 85-105 and 150-159 of mussel tropomyosin (GenBank/
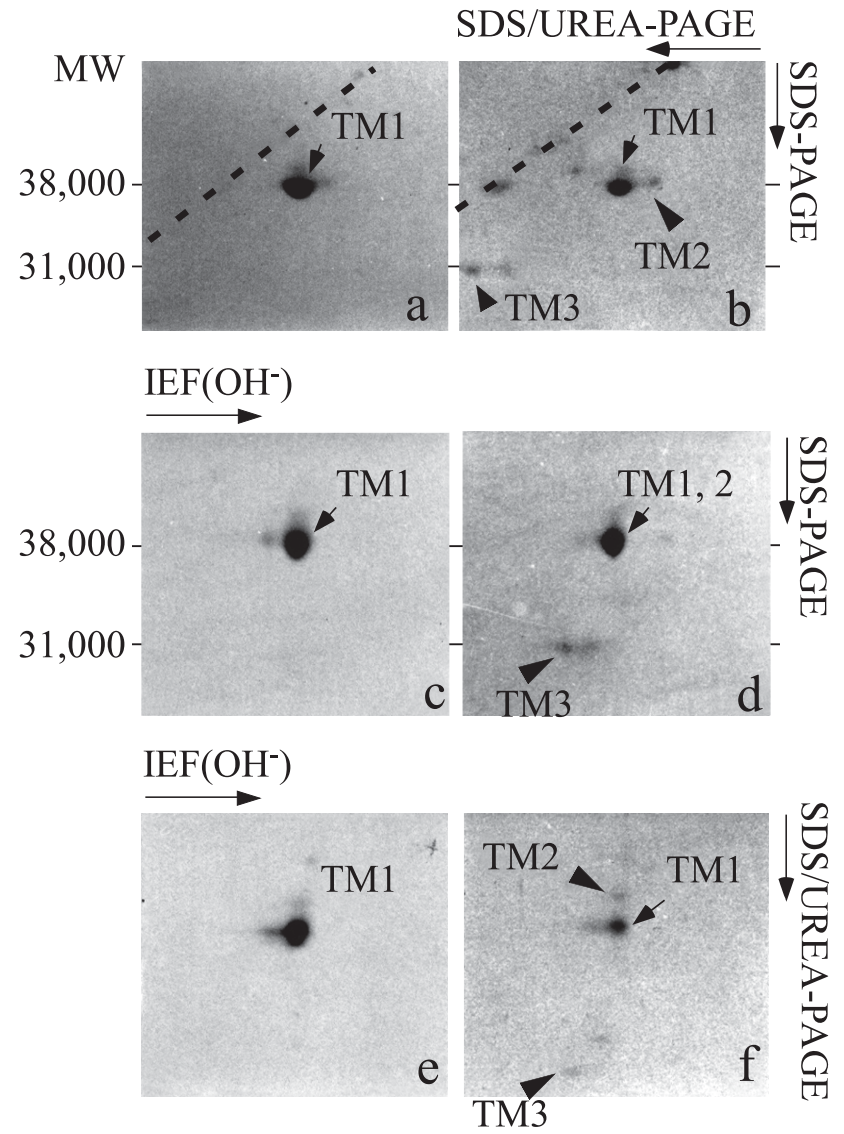

Fig. 5. Two dimensional gel electrophoresis of mussel tropomyosin isoforms.

Tropomyosin extracts prepared from the translucent portion of adductor muscle (a, c, e) and mantle (b, d, f) were analyzed with two-dimensional urea-shift gel electrophoresis (a, b) and two-dimensional gel electrophoresis with IEF and SDS gels (c, d), and with IEF and SDS/Urea gels (e, f). The numbers on the left of electrophoretogram (a) and (b) represent the molecular weight of TM1, TM2 and TM3, respectively. Arrows and arrowheads on each electrophoretogram show TM1, TM2 and TM3, respectively.

EMBL/DDBJ accession no. $\underline{\text { AB00907). }}$.

\section{DISCUSSION}

Several previous studies investigated that bivalve tropomyosin showed heterogeneity and tissue-specificity ${ }^{14-16)}$. Of the three tropomyosins found in two scallop species, $P$. yessoensis and M. nobilis ${ }^{15,16)}$, one is a striated-musclespecific isoform located in adductor striated muscle and the other two isoforms exist in the opaque portion of adductor smooth muscle. One of those two isoforms also exists in the translucent portion of adductor smooth muscle and the other also exists in cardiac muscle. Of species from the Veneroida, two tropomyosins have been found in M. lamarckii, T. keenae and M. Chinensis ${ }^{16)}$; one isoform exists in the translucent and opaque portions of adductor muscle and in cardiac muscle, and the other is opaque-portion-specific. Two tropomyosin isoforms have also been found in species from the Arcoida (S. broughtonii), the Pterioida (A. pecti- 
(A)

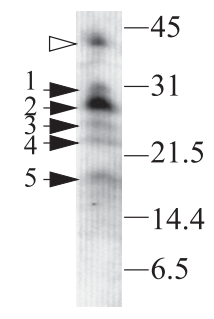

(B) fragment-1 : not analyzed

fragment-2 : EIQSLTDKXSXLEEDXXXSEER

fragment-3 : not analyzed

fragment- 4 : not analyzed

fragment-5 : EAQLXAEEAD

(C) M. galloprovincialis tropomyosin

MDA IKKKMVAMKMEKENALDRAEQLEQKLRETEEAKAK IEDDYNSLQKKS IQTENDLDNTQTQLQDVQAK 70

\author{
fragment-2 EIQSLTDKXSXLEEDXXXSEER \\ YETTEKQ IAEHEQË IOQSL̈TRK I SML̈̈ËD I MKS̈ËERYTTAASKLEEASKAADESERNRKVLENLNCGNDER 140 \\ IDQLEKQLTEAKWI AEEADKKYEEAARKLAITEVDLERAEARLEAAEAKV I DLEEQLTVVGAN IKTLQVQ 210 \\ $\because: \quad::::$ \\ fragment-5 EAQLXAEEAD
}

NDQASQREDSYEETIRDLTNRLKDAENRATEAERTVSKLRKEVDRLEDELLTEKEKYKAISDELDATFAE 280

\title{
LAGY 283
}

Fig. 6. Amino acid sequences of mussel tropomyosin.

Tropomyosin from adductor muscle was subjected to 15\% SDS-PAGE for limited proteolysis with V8 protease. Five proteolytic fragments, designated 1, 2, 3, 4 and 5, were obtained (A) and analyzed for their amino acid sequences (B). Only the sequences of fragments 2 and 6 could be obtained and they were EIQSLTDKXSXLEEDXXXSEER and EAQLXAEEAD, respectively, which corresponded to M. galloprovincialis tropomyo$\sin (\mathrm{C})$. The numbers in (C) show the position from the N-terminal amino acid sequence of mussel tropomyosin. Colons and dots respectively show the amino acid residues of the fragments that completely or partially identified with mussel tropomyosin.

nata) and the Ostreoida $(\text { C. gigas })^{14)}$. In S. broughtonii, one of two isoforms exists in the translucent portion of adductor muscle and the other in the opaque portion, and both forms are located in cardiac muscle. In A. pectinata, both isoforms exist in the translucent portion of adductor muscle, and one of them exists in both the opaque portion and in cardiac muscle. In $C$. gigas, both isoforms exist in the adductor muscle and cardiac muscle, but one of them is major isoform in adductor muscle and another is major isoform in cardiac muscle. Although it seems that the distribution of the tropomyosin isoforms in the two species of scallops is related to different muscle types and/or character, this is not the case for the other types of bivalves. If anything, the findings suggest that the distribution of tropomyosin isoforms in bivalves is associated with phylogenetic evolution ${ }^{14)}$. In bivalves, it was reported that mussel might be a close prototype ${ }^{27-29)}$. Interestingly, only one tropomyosin was found in adductor muscles and cardiac muscle of mussel in the previous study ${ }^{14)}$ and in the present study (Fig. 1 and 2). Because several tropomyosin isoforms were found in many bivalves ${ }^{14-16)}$, we examined whether mussel had only one tropomyosin. Although only one tropomyosin was found in major muscle tissue such as adductor muscle, cardiac muscle and retractor muscle, new two tropomyosin isoforms were found in mantle and gills (Fig. 2 and 4). Three mussel tropomyosins were designated TM1, TM2 and TM3, respectively. TM1 was major component in all tissue and may be the common isoform in mussel. TM2 was minor component and was mantle specific component. TM3 also was minor component and was mantle and gills specific component. Moreover, the molecular weight of TM3 was
Table 1. Qualities of each mussel tropomyosin isoform.

\begin{tabular}{|c|c|c|c|c|}
\hline & $\begin{array}{c}\text { Retardation by } \\
\text { Urea }\end{array}$ & $\begin{array}{c}\text { Detected } \\
\text { Tissues }\end{array}$ & $\begin{array}{l}\text { Molecular } \\
\text { Weight }\end{array}$ & $\mathrm{pI}$ \\
\hline TM1 & + & $\begin{array}{l}\text { retractor muscle, } \\
\text { adductor muscle, } \\
\text { cardiac muscle, } \\
\text { mantle, gills }\end{array}$ & 38,000 & 4.5 \\
\hline TM2 & ++ & mantle & 38,000 & 4.5 \\
\hline TM3 & + & mantle, gills & 31,000 & 4.5 \\
\hline
\end{tabular}

lower than that of TM1 and TM2. Because TM3 was a low molecular weight type and included in gills (Figs. 4 and 5), it is also likely that it is a non-muscle type isoform. In many cases, the non-muscle type of tropomyosin has a lower molecular weight because the $\mathrm{COOH}$-terminal is shorter than that of the muscle-type isoforms ${ }^{1,2}$. The $\mathrm{COOH}$ terminal of tropomyosin is involved in actin binding and polymerization $^{1,2)}$ and in the sea urchin the actin-binding ability of a non-muscle-type tropomyosin isoform was lower than that of a muscle type ${ }^{30)}$. Thus, the three tropomyosin isoforms in the mussel might differ in their actin-binding ability. Qualities of each mussel tropomyosin isoform found in the present study are shown in Table 1. From different qualities of each isoform, therefore, it is likely that mussel tropomyosin also show heterogeneity and tissue-specific distribution. In the present study, we could not suggest relationships between functions and structures of each isoform. A previous study has cloned one tropomyosin gene ${ }^{31}$, but as we have found three tropomyosin proteins in the mussel, we will screen for other genes in future studies. 


\section{ACKNOWLEDGMENTS}

The authors thank Dr Tadashi Ishimoda-Takagi (Department of Biology, Tokyo Gakugei University) for supplying the anti-M. nobilis tropomyosin antiserum. This work was partially supported by Keio Gijuku Academic Development Funds to A.I. from Keio University.

\section{REFERENCES}

1) Smillie LB. Structure and functions of tropomyosins from muscle and non-muscle sources. Trends Biochem Sci 1979;4:151-154.

2) Lees-Miller JP, Helfman DM. The molecular basis for tropomyosin isoform diversity. BioEssays 1991;13:429-437.

3) Pittenger MF, Kazzaz JA, Helfman DM. Functional properties of non-muscle tropomyosin isoforms. Curr Opin Cell Biol 1994;6:96-104.

4) Perry SV. Vertebrate tropomyosin: distribution, properties and function. J. Muscle Res Cell Motil 2001;22:5-49.

5) MacLeod AR, Houlker C, Reinach FC, Smillie LB, Talbot K, Modi G, Walsh FS. A muscle-type tropomyosin in human fibroblasts: Evidence for expression by an alternative RNA splicing mechanism. Proc Natl Acad Sci USA 1985;82:7835-7839.

6) Helfman DM, Cheley S, Kuismanen E, Finn LA, Yamawaki-Kataoka Y. Nonmuscle and muscle tropomyosin isoforms are expressed from a single gene by alternative RNA splicing and polyadenylation. Mol Cell Biol 1986;6:3582-3595.

7) Basi GS, Storti RV. Structure and DNA sequence of the tropomyosin I gene from Drosophila melanogaster. J Biol Chem 1986;261:817-827.

8) MacLeod AR. Genetic origin of diversity of human cytoskeletal tropomyosins. BioEssays 1987;6:208-212.

9) Wieczorek DF, Smith CWJ, Nadal-Ginard B. The rat $\alpha$ tropomyosin gene generates a minimum of six different mRNA coding for striated, smooth, and nonmuscle isoforms by alternative splicing. Mol Cell Biol 1988;8:679694.

10) Billeter R, Heizmann CW, Reist U, Howald H, Jenny E. $\alpha$ and $\beta$-tropomyosin in typed single fibers of human skeletal muscle. FEBS Letters 1981;132:133-136.

11) Montarras D, Fiszman MY, Gros, F. Characterization of the tropomyosin present in various chick embryo muscle type and in muscle cells differentiated in vitro. J Biol Chem 1981;256:4081-4086.

12) Heeley DH, Bieger T, Waddleton DM, Hong C, Jackman DM, McGowan C, Davidson WS, Beavis RC. Characterization of fast, slow and cardiac muscle tropomyosins from salmonid fish. Eur J Biochem 1995;232:226-234.

13) Ishimoda-Takagi $T$, Itoh $M$, Koyama H. Distribution of tropomyosin isoforms in spiny lobster muscles. J Exp Zool 1997;277:87-98.

14) Fujinoki $M$, Ueda $M$, Inoue $T$, Yasukawa $N$, Inoue $R$, Ishimoda-Takagi $\mathrm{T}$. Heterogeneity and tissue specificity of tropomyosin isoforms from four species of bivalves. Comp Biochem Physiol B 2006;143:500-506.
15) Ishimoda-Takagi T, Kobayashi M, Yaguchi M. Polymorphism and tissue specificity of scallop tropomyosin. Comp Biochem Physiol B 1986;83:515-521.

16) Ishimoda-Takagi $T$, Kobayashi M. Molecular heterogeneity and tissue specificity of tropomyosin obtain from various bivalves. Comp Biochem Physiol B 1987;88:443-452.

17) Ishimoda-Takagi $T$, Motohashi $A$, Ishikita S. Characterization of two distinct isoforms of tropomyosin present in the eggs of the sea urchin, Strongylocentrotus intermedius. Comp Biochem Physiol B 1990;95:403-413.

18) Fujinoki M, Tomiyama $T$, Ishimoda-Takagi $T$. Tropomyosin isoforms present in the sea anemone Anthopleura japonica (Anthozoa, Cnidaria). J Exp Zool 2002;293:649663.

19) Ishimoda-Takagi T, Ozaki S. Effect of trichloroacetic acid on the isolation of tropomyosin from sea urchin lantern muscle. J Biochem 1983;93:801-805.

20) Laemmli UK. Cleavage of structural proteins during assembly of the head of bacteriophage T4. Nature 1970;227:680-685.

21) Carmon Y, Neuman S, Yaffe D. Synthesis of tropomyosin in myogenic cultures and in RNA-directed cell-free systems: qualitative changes in the polypeptides. Cell 1978;14:393-401.

22) Hirabayashi T. Two-dimensional gel electrophoresis of chicken skeletal muscle proteins with agarose gels in the first dimension. Anal Biochem 1981;117:443-451.

23) Towbin H, Staehelin T, Gordon J. Electrophoretic transfer of protein from polyacrylamide gels to nitrocellulose sheets: Procedure and some applications. Proc Natl Acad Sci USA 1979;76:4350-4354.

24) Cleveland DW, Fischer SG, Kirschner MW, Laemmli UK. Peptide mapping by limited proteolysis in sodium dodecyl sulfate and analysis by gel electrophoresis. J Biol Chem 1977;252:1102-1106.

25) Sender PM. Muscle fibrils: Solubilization and gel electrophoresis. FEBS Lett 1971;17:106-110.

26) Weber K, Osborn M. The reliability of molecular weight determinations by dodecyl sulfate-polyacrylamide gel electrophoresis. J Biol Chem 1969;244:4406-4412.

27) Stanley MS. Functional morphology and evolution of byssally attached bivalve mollusks. J Paleontol 1972;46:165212.

28) Matsumoto M. Phylogenetic analysis of the subclass Pteriomorphia (Bivalvia) from mtDNA COI sequences. Mol Phylogenet Evol 2003;27:429-440.

29) Bieler R, Mikkelsen PM. Bivalvia-a look at the branches. Zool J Linn Soc 2006;148:223-235.

30) Tobita T, Hiraide F, Miyazaki J, Ishimoda-Takagi T. Muscle-type tropomyosin of sea urchin egg increases the actin-binding of nonmuscle-type tropomyosin. J Biochem 1996;120:922-928.

31) Iwasaki K, Kikuchi K, Funabara D, Watabe S. cDNA cloning of tropomyosin from the anterior byssus retractor muscle of mussel and its structural integrity from the deduced amino acid sequence. Fish Sci 1997;63:731-734. 